\title{
EZH2 expression is a prognostic biomarker in patients with colorectal cancer treated with anti-EGFR therapeutics
}

\author{
Itaru Yamamoto ${ }^{1, *}$, Katsuhiko Nosho ${ }^{1, *}$, Shinichi Kanno ${ }^{1, *}$, Hisayoshi Igarashi ${ }^{1, *}$, \\ Hiroyoshi Kurihara ${ }^{1}$, Keisuke Ishigami ${ }^{1}$, Kazuya Ishiguro ${ }^{1}$, Kei Mitsuhashi ${ }^{1}$, Reo \\ Maruyama², Hideyuki Koide ${ }^{1}$, Hiroyuki Okuda ${ }^{3}$, Tadashi Hasegawa ${ }^{4}$, Yasutaka \\ Sukawa1, Kenji Okita5, Ichiro Takemasa5, Hiroyuki Yamamoto6, Yasuhisa \\ Shinomura7, Hiroshi Nakase ${ }^{1}$ \\ ${ }^{1}$ Department of Gastroenterology and Hepatology, Sapporo Medical University School of Medicine, Sapporo, Japan \\ ${ }^{2}$ Department of Molecular Biology, Sapporo Medical University School of Medicine, Sapporo, Japan \\ ${ }^{3}$ Department of Oncology, Keiyukai Sapporo Hospital, Sapporo, Japan \\ ${ }^{4}$ Department of Surgical Pathology, Sapporo Medical University School of Medicine, Sapporo, Japan \\ ${ }^{5}$ Department of Surgery, Surgical Oncology and Science, Sapporo Medical University School of Medicine, Sapporo, Japan \\ ${ }^{6}$ Division of Gastroenterology and Hepatology, Department of Internal Medicine, St. Marianna University School of Medicine, \\ Kawasaki, Japan \\ ${ }^{7}$ Department of Gastroenterology, Ikeda Municipal Hospital, Ikeda, Japan \\ *These authors contributed equally to this work
}

Correspondence to: Katsuhiko Nosho, email: nosho@sapmed.ac.jp Keywords: $E Z H 2$, microRNA-31, colon cancer, EGFR, CIMP

Received: September 16, $2016 \quad$ Accepted: January 16, $2017 \quad$ Published: January 27, 2017

\section{ABSTRACT}

The polycomb group protein enhancer of zeste homolog 2 (EZH2) is a methyltransferase that suppresses microRNA-31 (miR-31) in various human malignancies including colorectal cancer. We recently suggested that miR-31 regulates the signaling pathway downstream of epidermal growth factor receptor (EGFR) in colorectal cancer. Therefore, we conducted this study for assessing the relationship between EZH2 expression and clinical outcomes in patients with colorectal cancer treated with anti-EGFR therapeutics. We immunohistochemically evaluated EZH2 expression and assessed miR-31 and gene mutations [KRAS (codon 61/146), NRAS (codon 12/13/61), and BRAF (codon 600)] in 109 patients with colorectal cancer harboring KRAS (codon 12/13) wild-type. We also evaluated the progression-free survival (PFS) and overall survival (OS). In the result, low EZH2 expression was significantly associated with shorter PFS (log-rank test: $P=0.023)$ and $0 S(P=0.036)$ in patients with colorectal cancer. In the low-miR31-expression group and the KRAS (codon 61/146), NRAS, and BRAF wild-type groups, a significantly shorter PFS $(P=0.022, P=0.039, P=0.021$, and $P=0.036$, respectively) was observed in the EZH2 low-expression groups than in the highexpression groups. In the multivariate analysis, low EZH2 expression was associated with a shorter PFS $(P=0.046)$, independent of the mutational status and miR-31. In conclusion, EZH2 expression was associated with survival in patients with colorectal cancer who were treated with anti-EGFR therapeutics. Moreover, low EZH2 expression was independently associated with shorter PFS in patients with cancer, suggesting that EZH2 expression is a useful additional prognostic biomarker for anti-EGFR therapy. 


\section{INTRODUCTION}

Monoclonal antibodies against the epidermal growth factor receptor (EGFR) have expanded the spectrum of therapeutic options; they have also improved the clinical outcome of patients with metastatic colorectal cancer [1-6]. The deregulation of the signaling pathways downstream of EGFR, including the RAS/RAF/MEK/ERK pathway, may induce resistance to anti-EGFR therapy. Regarding this resistance, a mutation in KRAS codon 61 or 146 has been actively studied as a possible additional predictive biomarker for anti-EGFR therapy $[6,7]$. In addition, several studies have suggested that mutations in certain genes (i.e., $N R A S$ and $B R A F$ ) account for this resistance [3-6, 8-16] because they are downstream effectors of the EGFR signaling pathway, similar to the KRAS gene. Therefore, there is a need to identify additional biomarkers to more accurate selection of patients for anti-EGFR therapy.

MicroRNAs have been increasingly recognized as useful biomarkers of various human cancers [17-22]. Regarding microRNA in the signaling pathway downstream of EGFR, we recently suggested that microRNA-31 (miR$31)-5 p$ regulates $B R A F$ activation in colorectal cancer $[23,24]$ and that high miR-31-5p is associated with survival in patients with colorectal cancer who underwent surgical treatment and chemotherapy with anti-EGFR antibodies [19].

The polycomb group protein enhancer of zeste homolog 2 (EZH2) is a methyltransferase and the core catalytic element of polycomb repressive complex 2 (PRC2), which plays a critical role in the regulation of cancer initiation, progression, invasion, metastasis, and drug resistance [25-27]. Various oncogenic transcription factors and cancer-associated noncoding RNAs including microRNA regulate EZH2 expression [19, 26, 28-31]. EZH2-mediated histone methylation suppresses miR-31 expression in prostate cancer [29] and adult T-cell leukemia [26]. Regarding colorectal cancer, we recently reported that EZH2 suppresses miR-31 expression by inducing histone $\mathrm{H} 3$ lysine 27 trimethylation (H3K27me3) on the miR-31 promoter and that EZH2 inhibition increased miR-31 expression [28].

Thus, accumulating evidence suggests that EZH2 is a useful and additional prognostic biomarker for anti-EGFR therapy in patients with colorectal cancer. Therefore, we conducted this study to assess the relation between EZH2 expression and clinical outcomes in patients with metastatic colorectal cancer treated with anti-EGFR therapeutics.

\section{RESULTS}

\section{EZH2 expression in 109 patients with colorectal cancer treated with anti-EGFR therapy}

The study included 115 patients with metastatic colorectal cancer who were received cetuximab or panitumumab. Immunohistochemistry for EZH2 expression were successfully performed in 109 (95\%) colorectal cancers.
We excluded six patients because of insufficient EZH2 staining. EZH2 expression scores of 0 (negative), 1 (weak), 2 (moderate), and 3 (strong) were observed in $11 \%, 21 \%$, $18 \%$, and $50 \%$ of the colorectal cancer tissues, respectively (Supplementary Figure 1).

\section{Association between EZH2 expression and clinical and molecular characteristics in colorectal cancer}

Of the 109 patients with colorectal cancer treated with anti-EGFR therapeutics, $50(46 \%)$ received cetuximab and 59 (54\%) received panitumumab. The regimen of cetuximab or panitumumab administration corresponded to first-line treatment in $16(15 \%)$ patients, second-line treatment in $17(16 \%)$ patients, and third-line treatment and beyond in $76(70 \%)$ patients.

Regarding miR-31-5p expression, 12 (11\%) patients and 97 (89\%) patients were classified into the high- and low-expression groups, respectively. The KRAS (codon 61/146), NRAS mutation (codon 12/13/61), and BRAF (codon 600) mutations were detected in $7(6.4 \%), 8$ (7.3\%), and $6(5.5 \%)$ patients, respectively.

Table 1 shows the clinicopathological and molecular features according to the EZH2 expression level. There were no significant associations between EZH2 expression and clinical or molecular features such as gender, age, tumor location, anti-EGFR therapeutics, anti-EGFR therapy line, $B R A F$ and $N R A S$ mutations. In contrast, a high EZH2 expression was inversely associated with $K R A S$ mutation (codon 61/146) $(P=0.0039)$. A high EZH2 expression was inversely associated with miR-31 expression; however, no significant relationship was found between them $(P=0.085)$.

\section{Expression of EZH2 and efficacy of anti-EGFR therapy in $K R A S$ (codon12/13) wild-type colorectal cancers}

During the follow-up study of the 109 patients with colorectal cancer treated with anti-EGFR therapeutics who were eligible for survival analysis, 64 patients died (all deaths were confirmed to be attributed to colorectal cancer). The median follow-up periods for Progressionfree survival (PFS) and overall survival (OS) were 6.1 and 46 months, respectively.

We made EZH2 into a dichotomous expression variable, defining scores of 2-3 as high-expression and those of $0-1$ as low-expression. The median PFS and OS in the EZH2 low-expression group were 3.7 and 31 months, while those in the EZH2 high-expression group were 6.1 and 55 months, respectively. In terms of PFS, a significantly shorter PFS was observed in patients in the low-expression group (log-rank test: $P=0.023$ ) than in those in the highexpression group (Figure 1A). Additionally, there was a significant difference in OS $(P=0.036)$ between the EZH2 low-(scores of 0-1) and high- (scores of 2-3) expression 
Table 1: Clinicopathological or molecular features of 109 colorectal cancer patients who received anti-EGFR therapy

\begin{tabular}{|c|c|c|c|c|c|c|}
\hline \multirow{2}{*}{$\begin{array}{l}\text { Clinicopathological or } \\
\text { molecular feature }\end{array}$} & \multirow[b]{2}{*}{ Total $\mathbf{N}$} & \multicolumn{4}{|c|}{ EZH2 expression } & \multirow[b]{2}{*}{$P$} \\
\hline & & $\begin{array}{c}\text { score } 0 \\
\text { (negative) }\end{array}$ & $\begin{array}{l}\text { score } 1 \\
\text { (weak) }\end{array}$ & $\begin{array}{c}\text { score } 2 \\
\text { (moderate) }\end{array}$ & $\begin{array}{l}\text { score } 3 \\
\text { (strong) }\end{array}$ & \\
\hline All cases & 109 & $12(11 \%)$ & $23(21 \%)$ & $20(18 \%)$ & $54(50 \%)$ & \\
\hline \multicolumn{7}{|l|}{ Gender } \\
\hline Male & $76(70 \%)$ & $7(58 \%)$ & $16(69 \%)$ & $14(70 \%)$ & $39(72 \%)$ & \multirow{2}{*}{0.84} \\
\hline Female & $33(30 \%)$ & $5(42 \%)$ & $7(30 \%)$ & $6(30 \%)$ & $15(28 \%)$ & \\
\hline Age $($ mean $\pm \mathrm{SD})$ & $60.5 \pm 11.6$ & $61.9 \pm 8.2$ & $62.1 \pm 13.0$ & $60.4 \pm 9.2$ & $59.6 \pm 12.4$ & 0.82 \\
\hline \multicolumn{7}{|l|}{ Tumor location } \\
\hline $\begin{array}{l}\text { Distal colon (splenic flexure to } \\
\text { sigmoid colon) and Rectum }\end{array}$ & $82(75 \%)$ & $5(42 \%)$ & $17(74 \%)$ & $13(65 \%)$ & $47(87 \%)$ & \multirow[b]{2}{*}{0.0082} \\
\hline $\begin{array}{l}\text { Proximal colon (cecum to } \\
\text { transverse colon) }\end{array}$ & $27(25 \%)$ & $7(58 \%)$ & $6(26 \%)$ & $7(35 \%)$ & $7(13 \%)$ & \\
\hline \multicolumn{7}{|l|}{ Anti-EGFR agents } \\
\hline Cetuximab & $50(46 \%)$ & $5(42 \%)$ & $11(48 \%)$ & $9(45 \%)$ & $25(46 \%)$ & \multirow{2}{*}{0.99} \\
\hline Panitumumab & $59(54 \%)$ & $7(58 \%)$ & $12(52 \%)$ & $11(55 \%)$ & $29(54 \%)$ & \\
\hline \multicolumn{7}{|l|}{ Line of anti-EGFR therapy } \\
\hline First line & $16(15 \%)$ & $0(0 \%)$ & $2(8.7 \%)$ & $3(15 \%)$ & $11(20 \%)$ & \multirow{3}{*}{0.18} \\
\hline Second line & $17(16 \%)$ & $2(17 \%)$ & $6(26 \%)$ & $4(20 \%)$ & $5(9.3 \%)$ & \\
\hline Third line and beyond & $76(70 \%)$ & $10(83 \%)$ & $15(65 \%)$ & $13(65 \%)$ & $38(70 \%)$ & \\
\hline \multicolumn{7}{|l|}{$B R A F$ mutation (codon 600$)$} \\
\hline Wild-type & $103(95 \%)$ & $11(92 \%)$ & $22(96 \%)$ & $19(95 \%)$ & $51(94 \%)$ & \multirow{2}{*}{0.97} \\
\hline Mutant & $6(5.5 \%)$ & $1(8.3 \%)$ & $1(4.4 \%)$ & $1(5.0 \%)$ & $3(5.6 \%)$ & \\
\hline \multicolumn{7}{|l|}{ KRAS mutation (codon 61/146) } \\
\hline Wild-type & $102(94 \%)$ & $9(75 \%)$ & $22(96 \%)$ & $17(85 \%)$ & $54(100 \%)$ & \multirow{2}{*}{0.0039} \\
\hline Mutant & $7(6.4 \%)$ & $3(25 \%)$ & $1(4.4 \%)$ & $3(15 \%)$ & $0(0 \%)$ & \\
\hline \multicolumn{7}{|l|}{ NRAS mutation (codon 12/13/61) } \\
\hline Wild-type & $101(93 \%)$ & $12(100 \%)$ & $21(91 \%)$ & $19(95 \%)$ & $49(91 \%)$ & \multirow{2}{*}{0.50} \\
\hline Mutant & $8(7.3 \%)$ & $0(0 \%)$ & $2(8.7 \%)$ & $1(5.0 \%)$ & $5(9.3 \%)$ & \\
\hline \multicolumn{7}{|l|}{ MicroRNA-31-5p expression } \\
\hline Low-expression & $97(89 \%)$ & $8(67 \%)$ & $21(91 \%)$ & $17(85 \%)$ & $51(94 \%)$ & \multirow{2}{*}{0.085} \\
\hline High-expression & $12(11 \%)$ & $4(33 \%)$ & $2(8.7 \%)$ & $3(15 \%)$ & $3(5.6 \%)$ & \\
\hline
\end{tabular}

Percentage (\%) indicates the proportion of cases with a specific clinicopathological or molecular feature within a given dichotomous category of EZH2 expression by immunohistochemistry. $P$ values were calculated by analysis of variance for age and by a chi-square test or Fisher's exact test for all other variables.

EGFR, epidermal growth factor receptor; SD, standard deviation.

groups (Figure 1B). In the univariate Cox regression analysis, a significantly shorter PFS [hazard ratio (HR): $1.79 ; 95 \%$ confidence interval (CI): $1.06-2.98 ; P=0.029)]$ and OS (HR: $1.69 ; 95 \%$ CI: $1.02-2.76 ; P=0.042)$ were observed in the low-expression group (scores of 0-1) than in the high-expression group (scores of 2-3).

\section{Expression of EZH2 and efficacy of anti-EGFR therapy according to mutational status in $K R A S$ (codon 12/13) wild-type colorectal cancers}

We further analyzed the association of EZH2 expression with the efficacy of anti-EGFR therapy in 
patients with colorectal cancer with no mutations in KRAS (codon 61/146), NRAS (codon 12/13/61), or BRAF (codon 600). In the KRAS (codon 61/146), NRAS, and BRAF wildtype groups, a significantly shorter PFS (log-rank test: $P=0.039, P=0.021$, and $P=0.036$, respectively) was observed in the EZH2 low-expression groups (scores of 0-1) than in the high-expression groups (scores of 2-3) in Kaplan-Meier analysis (Figure 2). We also examined the PFS for the group with at least one mutation in $K R A S$, $N R A S$, or $B R A F$ and the no-mutation group. As a result, in the no-mutation group, our data indicated a tendency for a significant difference between the EZH2 high- and lowexpression groups in Kaplan-Meier analysis $(P=0.057)$.

Regarding OS, significant differences were observed according to EZH2 expression in the NRAS (log-rank test: $P=0.017)$, and $B R A F$ (log-rank test: $P=0.029)$ wild-type groups; however, no significant difference was observed between the low- and high-expression groups in the KRAS wild-type group (codon 61/146; log-rank test: $P=0.22$ ) (Supplementary Figure 2).

\section{Expression of miR-31 and efficacy of anti-EGFR therapy in $K R A S(\operatorname{codon} 12 / 13)$ wild-type group colorectal cancers}

In the miR-31 low-expression group, a significantly shorter PFS (log-rank test: $P=0.022$ ) was observed in the EZH2 low-expression group (scores of 0-1) than in the high-expression group (scores of 2-3) in Kaplan-Meier analysis (Figure 3). Similarly, in the miR-31 low-expression group, a significant difference was observed in OS according to EZH2 expression (log-rank test: $P=0.048$ ) (Figure 3 ).

\section{Multivariate cox regression analysis for PFS and OS according to EZH2 expression in colorectal cancers}

In the multivariate Cox regression analysis for PFS, a significantly shorter PFS was observed in the EZH2 lowexpression group (scores of $0-1$ ) than in the high-expression group (scores of 2-3) (HR: 1.73; 95\% CI: 1.01-2.92; $P=0.046$ ) (Table 2). Regarding OS, a poorer prognosis was observed in the EZH2 low-expression group than in the high-expression group, although no significant difference was found between them (HR: 1.56; 95\% CI: 0.93-2.58; $P=0.093$ ) (data not shown).

\section{DISCUSSION}

In the current study on patients with colorectal cancer who underwent surgical treatment, we elucidated the association of EZH2 expression, gene mutations, or miR-31 expression in the pathway downstream of EGFR with the efficacy of anti-EGFR therapy. Low EZH2 expression was significantly associated with a shorter PFS and OS in patients with KRAS (codon 12/13) wildtype group colorectal cancer treated with anti-EGFR therapeutics. Moreover, low EZH2 expression was associated with shorter PFS, independent of the mutations of $B R A F$ (codon 600), KRAS (codon 61/146), and NRAS
(A) PFS according to EZH2 expression
in all cases $(\mathrm{N}=109)$

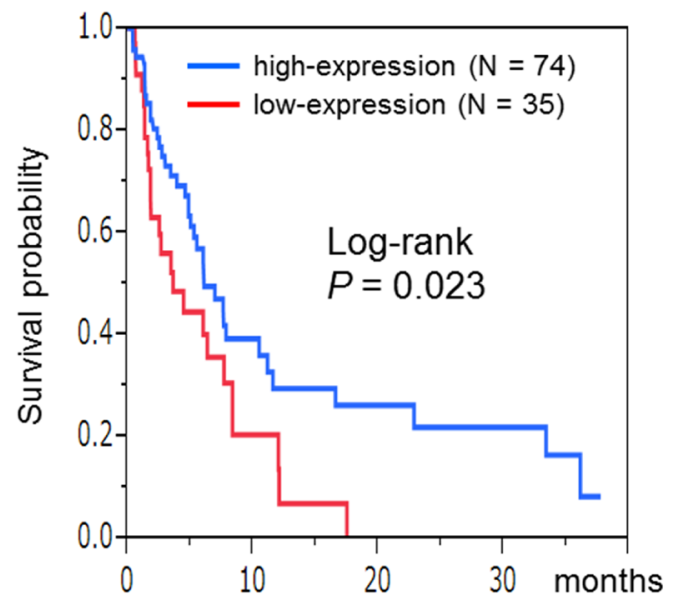

(B) OS according to EZH2 expression in all cases $(\mathrm{N}=109)$

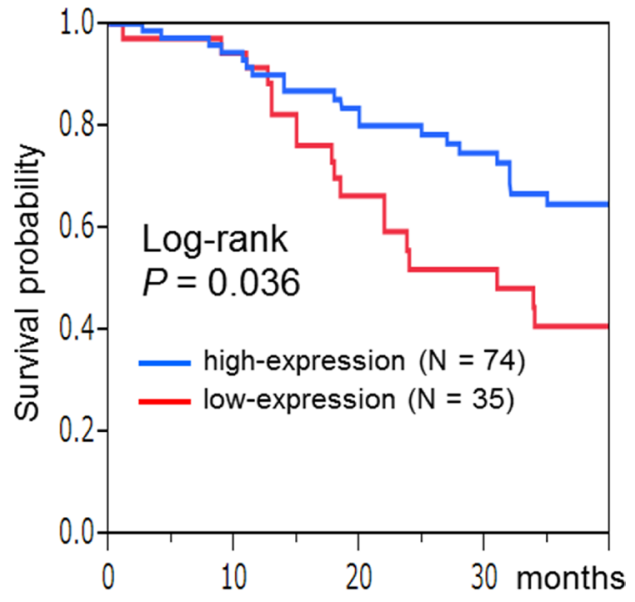

\begin{tabular}{|lccccccc|}
\hline $\begin{array}{l}\text { EZH2 } \\
\text { score }\end{array}$ & \multicolumn{1}{c|}{ Numbers at risk (month) } \\
\hline low & 35 & 11 & 6 & 1 & 0 & & \\
high & 74 & 34 & 14 & 10 & 8 & 6 & 5 \\
\hline
\end{tabular}

\begin{tabular}{|llllllll|}
\hline $\begin{array}{l}\text { EZH2 } \\
\text { score }\end{array}$ & \multicolumn{4}{|c|}{ Numbers at risk (month) } \\
\hline low & 35 & 35 & 34 & 27 & 20 & 15 & 15 \\
high & 74 & 71 & 67 & 55 & 49 & 45 & 40 \\
\hline
\end{tabular}

Figure 1: Kaplan-Meier survival curves of patients treated with anti-EGFR therapeutics in all cases $(N=109)$. (A) Progression-free survival of the EZH2 low-expression group versus that of the high-expression group. (B) Overall survival of the EZH2 low-expression group versus that of the high-expression group. 
Table 2: Multivariate Cox regression analysis of colorectal cancer patients treated with antiEGFR therapy

\begin{tabular}{|c|c|c|c|c|}
\hline & \multicolumn{4}{|c|}{ Progression-free survival } \\
\hline & $\begin{array}{l}\text { Median } \\
\text { (months) }\end{array}$ & $\begin{array}{l}\text { Hazard } \\
\text { ratio }\end{array}$ & $\begin{array}{l}95 \% \\
\text { confidence } \\
\text { interval }\end{array}$ & $P$ \\
\hline $\begin{array}{l}\text { NRAS mutation (codon } 12 / 13 / 61 \text { ) } \\
\text { (mutated group vs. wild-type group) }\end{array}$ & 2.6 vs. 6.1 & 3.62 & $1.32-8.50$ & 0.015 \\
\hline $\begin{array}{l}\text { EZH2 expression } \\
\text { (low-expression group vs. high-expression group) }\end{array}$ & 3.7 vs. 6.1 & 1.73 & $1.01-2.92$ & 0.046 \\
\hline $\begin{array}{l}B R A F \text { mutation (codon } 600 \text { ) } \\
\text { (mutated group vs. wild-type group) }\end{array}$ & 2.0 vs. 6.1 & 2.97 & $0.86-7.87$ & 0.080 \\
\hline $\begin{array}{l}\text { KRAS mutation (codon } 61 / 146 \text { ) } \\
\text { (mutated group vs. wild-type group) }\end{array}$ & 2.5 vs. 6.1 & 2.93 & $0.66-9.19$ & 0.14 \\
\hline $\begin{array}{l}\text { Tumor location } \\
\text { [Proximal colon (cecum to transverse colon) vs. } \\
\text { Distal colon (splenic flexure to sigmoid colon) and Rectum] }\end{array}$ & 4.9 vs. 6.1 & 1.61 & $0.84-2.96$ & 0.15 \\
\hline $\begin{array}{l}\text { MicroRNA-31 expression } \\
\text { (high-expression group vs. low-expression group) }\end{array}$ & 4.5 vs. 6.1 & 1.18 & $0.55-2.33$ & 0.65 \\
\hline
\end{tabular}

EGFR, epidermal growth factor receptor.

(codon 12/13/61) mutations and miR-31 expression. Thus, our data suggest that EZH2 expression is a useful biomarker for anti-EGFR therapy in patients with colorectal cancer.

It is well established that mutations in $K R A S$ codon 12 or 13 are predictive of a lack of response to anti-EGFR therapy $[1,2,32]$. Recent studies have demonstrated a correlation between mutation in KRAS codons 61 or 146 $[3,6,7]$ and resistance to anti-EGFR therapy. Moreover, as additional RAS-activating mutations, NRAS mutations have been reported to predict the response in patients with colorectal cancer treated with anti-EGFR therapeutics [3, $6,33-35]$. BRAF has also been reported to demonstrate a correlation between mutation and resistance to treatment with anti-EGFR therapy $[4,5,7,10,13,36]$. Regarding the association between microRNA expression and resistance to treatment with anti-EGFR therapy, we recently suggested that high miR-31-5p expression is a useful and additional prognostic biomarker for anti-EGFR therapy [19].

Our current data showed a significantly shorter PFS and $\mathrm{OS}$ in the EZH2 low-expression group than in the high-expression group, not only in the wild-type groups of $K R A S$ (codon 61/146), NRAS, and BRAF but also in the miR-31 low-expression group. In addition, the present multivariate analysis including the variable of EZH2 expression stratified by miR-31 and mutations of $B R A F$, $K R A S$, and $N R A S$ showed a significantly shorter PFS in the $\mathrm{EZH} 2$ low-expression group than in the high-expression group. To our knowledge, this is the first report describing the association between the expression of EZH2 and efficacy of anti-EGFR therapy in colorectal cancer. Unlike

\section{(A)}

PFS according to $\mathrm{EZH} 2$ expression

in KRAS (codon 61/146) wild-type group $(N=102)$

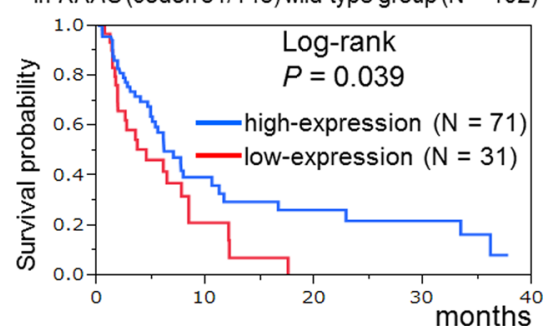

(B)

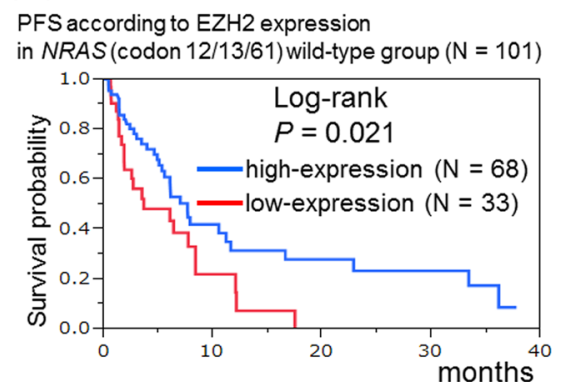

(C)

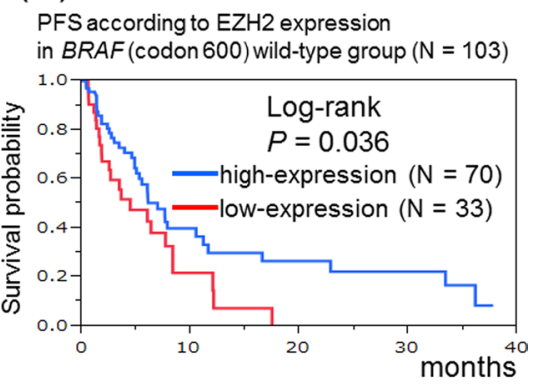

Figure 2: Kaplan-Meier survival curves of patients treated with anti-EGFR therapeutics in wild-type groups of $K R A S$ (codon 61/146), NRAS (codon 12/13/61), and BRAF (codon 600). (A) Progression-free survival according to EZH2 expression in the $K R A S$ wild-type group $(N=102)$. (B) Progression-free survival according to EZH2 expression in the $N R A S$ wild-type group $(N=101)$. (C) Progression-free survival according to EZH2 expression in the $B R A F$ wild-type group $(N=103)$. 
our previous report using colorectal cancer $(N=301)$ [28], no significant association was found between EZH2 and miR-31 expression, although there was a trend $(P=$ $0.085)$. The reason for this discrepancy may have been the small sample size in the current study $(N=109)$.

Regarding the association between EZH2 expression and the signaling pathway downstream of EGFR, Riquelme et al. recently reported that oncogenic $K R A S$ regulates $\mathrm{EZH} 2$ expression in lung cancer and that different amino acid substitutions in KRAS mutants differentially modulate EZH2 expression [25]. These results suggest that EZH2 inhibitory strategies can be combined with MEK/ERK-targeted therapies to treat patients with lung cancer. Additionally, they also extended these findings to colon and pancreatic cancers and obtained similar results. Our current study showed a significant correlation between EZH2 expression and $K R A S$ (codon 61/146) mutation in colorectal cancers. These findings suggest that oncogenic KRAS mutations in different kinds of tumors differentially modulate EZH2 expression through the signaling pathway downstream of EGFR. Further functional analysis is required for clarifying the regulatory role of EZH2 in the signaling pathway downstream of EGFR in colorectal cancer.

There are some limitations to our study. These include the cross-sectional and observational design and the relatively small sample size for prognostic analysis. In addition, all patients underwent resection of the primary lesion of colorectal cancer before chemotherapy. These limitations may have affected the prognostic analysis; OS of patients with colorectal cancer was relatively longer than that obtained in large clinical trials. In contrast, our current study showed that there was a significantly better PFS in colorectal cancers possessing all wild-type copies of $K R A S, N R A S$, and $B R A F$ than in colorectal cancers with at least one mutation of $K R A S, N R A S$, and $B R A F$, although no significant differences in OS were observed between them (data not shown). These findings are almost consistent with those of previous studies [3, 5, 13, 16, 34] and support the validity of our pyrosequencing assay for examining the gene mutations in the pathway downstream of EGFR. Future large and independent studies are necessary for confirming the correlation between low EZH2 expression and unfavorable prognosis in patients with metastatic colorectal cancer who have received antiEGFR therapy.

In conclusion, we found that EZH2 expression was associated with survival in patients with metastatic colorectal cancer who underwent surgical treatment and chemotherapy with anti-EGFR antibodies. Moreover, low EZH2 expression was associated with a shorter PFS in patients with colorectal cancer, independent of gene mutations in the downstream part of the EGFR pathway and miR-31 expression, suggesting that EZH2 expression is a useful and additional prognostic biomarker for antiEGFR therapy.

\section{MATERIALS AND METHODS}

\section{Patients and tissue specimens}

We collected formalin-fixed paraffin-embedded (FFPE) tissues of 109 primary tumors of colorectal cancers of patients who underwent surgical treatment
(A) PFS according to EZH2 expression in miR-31 low expression group $(\mathrm{N}=97)$

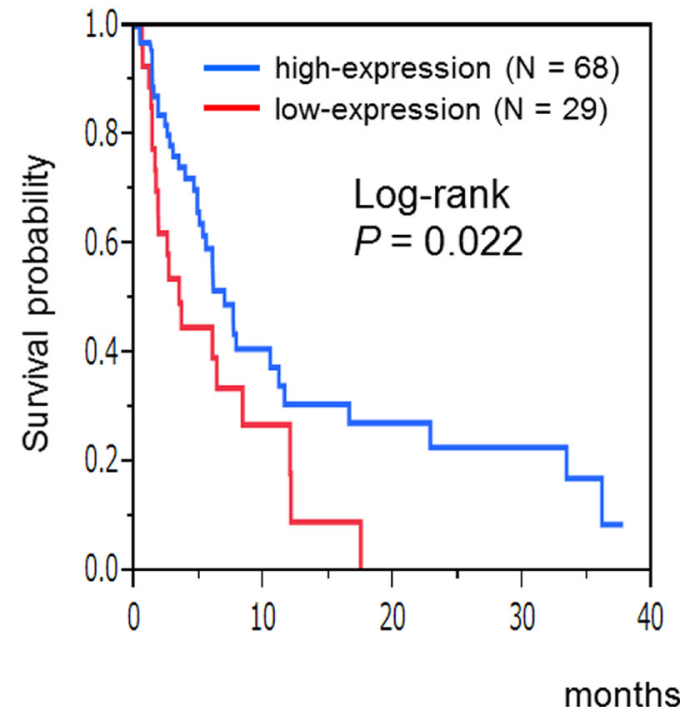

(B) OS according to EZH2 expression in miR-31 low expression group $(\mathrm{N}=97)$

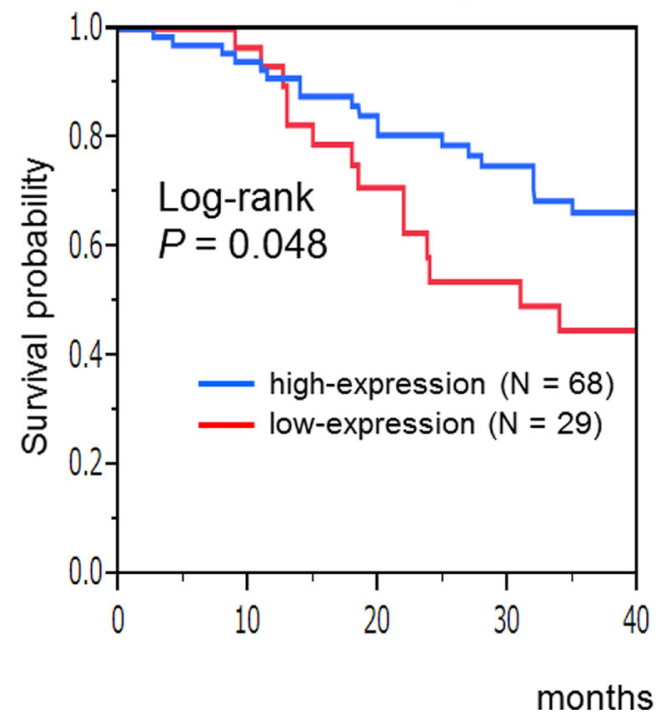

Figure 3: Kaplan-Meier survival curves of patients treated with anti-EGFR therapeutics in the microRNA-31 (miR31)-5p low-expression group $(\boldsymbol{N}=\mathbf{9 7})$. (A) Progression-free survival according to EZH2 expression in the miR-31 low-expression group. (B) Overall survival according to EZH2 expression in the miR-31 low-expression group. 
and chemotherapy with anti-EGFR antibodies at Sapporo Medical University Hospital or Keiyukai Sapporo Hospital between 1997 and 2014. All patients underwent surgical resection of primary tumor of colorectal cancer before receiving anti-EGFR therapy. To clarify the association between EZH2 expression and survival in patients with metastatic colorectal cancer, we limited the patients who received 5-FU-based adjuvant chemotherapy before receiving anti-EGFR therapy. The primary cancer tissues of all patients were confirmed to be both histologically EGFRpositive and without mutations in KRAS codons 12 and 13.

PFS was defined as the time from the beginning of anti-EGFR therapy to progression or death by any cause. Patients who did not meet these criteria were censored at the date of last administration. OS was defined as the time from the diagnosis of colorectal cancer to death by any cause or last follow-up. The patients were followed until death or December 2014, whichever came first. Informed consent was obtained from all patients before specimen collection. This study was approved by the institutional review boards of the participating institutions.

\section{RNA extraction from FFPE tissues and quantitative reverse transcription-PCR of microRNA}

Total RNA was extracted from FFPE tissues using the miRNeasy FFPE Kit (Qiagen, Valencia, CA, USA) [23]. MiR-31-5p expression was analyzed by quantitative reverse transcription-PCR (qRT-PCR) using TaqMan MicroRNA Reverse Transcription Kit (Applied Biosystems, Foster City, CA, USA) and TaqMan microRNA Assays (Applied Biosystems) as previously described [23].

\section{Pyrosequencing of $B R A F, K R A S$, and $N R A S$ mutations}

Using extracted genomic DNA, PCR and targeted pyrosequencing were performed for $B R A F$ (codon 600) [37], KRAS (codon 12/13/61/146) [19], and NRAS (codon 12/13/61) [33].

\section{Immunohistochemistry for EZH2 expression}

Immunohistochemistry was performed on $5 \mu \mathrm{m}$ FFPE sections. Sections were autoclave-pretreated in target retrieval solution (Dako Cytomation, Carpinteria, CA, USA). Endogenous peroxidase activity was blocked using $3 \%$ hydrogen peroxide, and the sections were incubated with anti-EZH2 antibody as previously described [28]. Five random high-power fields were evaluated per lesion to determine the mean nuclear positivity, which was categorized as follows: score 0 (negative, $<5 \%$ ), score 1 (weak, $5 \%-39 \%$ ), score 2 (moderate, $40 \%-79 \%$ ), or score 3 (strong, $\geq 80 \%$ ).

\section{Statistical analysis}

JMP (version 10) software was used for statistical analysis (SAS Institute, Cary, NC, USA). All $P$ values were 2-sided. Univariate analysis was performed to assess clinicopathological and molecular characteristics according to the EZH2 expression level; the chi-square test or Fisher's exact test was used for categorical data, whereas analysis of variance was used to compare the mean patient age.

In survival analysis, the Kaplan-Meier method and log-rank test were used to assess survival time distribution. Cox proportional hazards regression models were used to compute mortality hazard ratio according to the EZH2 expression status. The multivariate Cox model included the variable of EZH2 expression stratified by tumor location (proximal colon vs. distal colon and rectum), the mutations of BRAF (codon 600), KRAS (codon 61/146), and NRAS (codon 12/13/61) (present vs. absent), and miR-31 (highexpression vs. low-expression). A backward elimination was performed with a threshold of $P=0.10$, to avoid overfitting.

\section{Abbreviations}

CI, confidence interval; EGFR, epidermal growth factor receptor; $\mathrm{EZH} 2$, enhancer of zeste homolog 2; FFPE, formalin-fixed, paraffin-embedded; HR, hazard ratio; H3K27me3, histone $\mathrm{H} 3$ lysine 27 trimethylation; miR-31, microRNA-31; OS, overall survival; PFS, progression-free survival; SD, standard deviation.

\section{ACKNOWLEDGMENTS}

We thank the pathology departments of Sapporo Medical University Hospital and Keiyukai Sapporo Hospital for providing the tissue specimens.

\section{CONFLICTS OF INTEREST}

No conflicts of interest.

\section{GRANT SUPPORT}

This work was supported by The Japanese Society of Gastroenterology Research Foundation (to KN), Project Mirai Cancer Research Grants (to KN), Takeda Science Foundation (to KN), Daiwa Securities Health Foundation (to KN), Kobayashi Foundation for Cancer Research (to $\mathrm{KN}$ ), Sapporo Jikeikai Tomoiki Foundation (to SK), and The Japan Society for the Promotion of Science (JSPS) Grant-inAid for Scientific Research (grant number 15K08954 to YS).

\section{Authors' contributions}

Study concept and design: KN, IY, HI, HK; Data acquisition: SK, KI, KI, KM, HK; Data analysis and 
interpretation: KN, YS, HI; Drafting of the manuscript: $\mathrm{KN}, \mathrm{HI}, \mathrm{HK}$; Critical revision of the manuscript for important intellectual content: KN, HY, YS, RM, HN; Statistical analysis: HI, KN; Material support: HO, TH, KO, IT; Study supervision: KN, IY, IT, YS, HN; Final approval of manuscript: all authors.

\section{REFERENCES}

1. Karapetis CS, Khambata-Ford S, Jonker DJ, O'Callaghan CJ, Tu D, Tebbutt NC, Simes RJ, Chalchal H, Shapiro JD, Robitaille S, Price TJ, Shepherd L, Au HJ, et al. $\mathrm{K}$-ras mutations and benefit from cetuximab in advanced colorectal cancer. N Engl J Med. 2008; 359:1757-1765.

2. Amado RG, Wolf M, Peeters M, Van Cutsem E, Siena S, Freeman DJ, Juan T, Sikorski R, Suggs S, Radinsky R, Patterson SD, Chang DD. Wild-type KRAS is required for panitumumab efficacy in patients with metastatic colorectal cancer. J Clin Oncol. 2008; 26:1626-1634.

3. De Roock W, Claes B, Bernasconi D, De Schutter J, Biesmans B, Fountzilas G, Kalogeras KT, Kotoula V, Papamichael D, Laurent-Puig P, Penault-Llorca F, Rougier P, Vincenzi B, et al. Effects of KRAS, BRAF, NRAS, and PIK3CA mutations on the efficacy of cetuximab plus chemotherapy in chemotherapy-refractory metastatic colorectal cancer: a retrospective consortium analysis. Lancet Oncol. 2010; 11:753-762.

4. Laurent-Puig P, Cayre A, Manceau G, Buc E, Bachet JB, Lecomte T, Rougier P, Lievre A, Landi B, Boige V, Ducreux M, Ychou M, Bibeau F, et al. Analysis of PTEN, BRAF, and EGFR status in determining benefit from cetuximab therapy in wild-type KRAS metastatic colon cancer. J Clin Oncol. 2009; 27:5924-5930.

5. Bardelli A, Siena S. Molecular mechanisms of resistance to cetuximab and panitumumab in colorectal cancer. J Clin Oncol. 2010; 28:1254-1261.

6. Douillard JY, Oliner KS, Siena S, Tabernero J, Burkes R, Barugel M, Humblet Y, Bodoky G, Cunningham D, Jassem J, Rivera F, Kocakova I, Ruff $\mathrm{P}$, et al. PanitumumabFOLFOX4 treatment and RAS mutations in colorectal cancer. N Engl J Med. 2013; 369:1023-1034.

7. Loupakis F, Ruzzo A, Cremolini C, Vincenzi B, Salvatore L, Santini D, Masi G, Stasi I, Canestrari E, Rulli E, Floriani I, Bencardino K, Galluccio N, et al. KRAS codon 61, 146 and BRAF mutations predict resistance to cetuximab plus irinotecan in KRAS codon 12 and 13 wild-type metastatic colorectal cancer. Br J Cancer. 2009; 101:715-721.

8. De Roock W, Piessevaux H, De Schutter J, Janssens M, De Hertogh G, Personeni N, Biesmans B, Van Laethem JL, Peeters M, Humblet Y, Van Cutsem E, Tejpar S. KRAS wild-type state predicts survival and is associated to early radiological response in metastatic colorectal cancer treated with cetuximab. Ann Oncol. 2008; 19:508-515.

9. Blanke CD, Goldberg RM, Grothey A, Mooney M, Roach N, Saltz LB, Welch JJ, Wood WA, Meropol NJ, Force
NGSCCCT. KRAS and colorectal cancer: ethical and pragmatic issues in effecting real-time change in oncology clinical trials and practice. Oncologist. 2011; 16:1061-1068.

10. Di Nicolantonio F, Martini M, Molinari F, Sartore-Bianchi A, Arena S, Saletti P, De Dosso S, Mazzucchelli L, Frattini M, Siena S, Bardelli A. Wild-type BRAF is required for response to panitumumab or cetuximab in metastatic colorectal cancer. J Clin Oncol. 2008; 26:5705-5712.

11. Loupakis F, Pollina L, Stasi I, Ruzzo A, Scartozzi M, Santini D, Masi G, Graziano F, Cremolini C, Rulli E, Canestrari E, Funel N, Schiavon G, et al. PTEN expression and KRAS mutations on primary tumors and metastases in the prediction of benefit from cetuximab plus irinotecan for patients with metastatic colorectal cancer. J Clin Oncol. 2009; 27:2622-2629.

12. De Roock W, Lambrechts D, Tejpar S. K-ras mutations and cetuximab in colorectal cancer. N Engl J Med. 2009; 360:834; author reply 835-836.

13. Saridaki Z, Tzardi M, Papadaki C, Sfakianaki M, Pega F, Kalikaki A, Tsakalaki E, Trypaki M, Messaritakis I, Stathopoulos E, Mavroudis D, Georgoulias V, Souglakos J. Impact of KRAS, BRAF, PIK3CA mutations, PTEN, AREG, EREG expression and skin rash in $>/=2$ line cetuximabbased therapy of colorectal cancer patients. PLoS One. 2011; 6:e15980.

14. Sood A, McClain D, Maitra R, Basu-Mallick A, Seetharam R, Kaubisch A, Rajdev L, Mariadason JM, Tanaka K, Goel S. PTEN gene expression and mutations in the PIK3CA gene as predictors of clinical benefit to anti-epidermal growth factor receptor antibody therapy in patients with KRAS wild-type metastatic colorectal cancer. Clin Colorectal Cancer. 2012; 11:143-150.

15. Prenen H, De Schutter J, Jacobs B, De Roock W, Biesmans B, Claes B, Lambrechts D, Van Cutsem E, Tejpar S. PIK3CA mutations are not a major determinant of resistance to the epidermal growth factor receptor inhibitor cetuximab in metastatic colorectal cancer. Clin Cancer Res. 2009; 15:3184-3188.

16. Pentheroudakis G, Kotoula V, De Roock W, Kouvatseas G, Papakostas P, Makatsoris T, Papamichael D, Xanthakis I, Sgouros J, Televantou D, Kafiri G, Tsamandas AC, Razis E, et al. Biomarkers of benefit from cetuximab-based therapy in metastatic colorectal cancer: interaction of EGFR ligand expression with RAS/RAF, PIK3CA genotypes. BMC Cancer. 2013; 13:49.

17. Inoue A, Yamamoto H, Uemura M, Nishimura J, Hata T, Takemasa I, Ikenaga M, Ikeda M, Murata K, Mizushima T, Doki Y, Mori M. MicroRNA-29b is a Novel Prognostic Marker in Colorectal Cancer. Ann Surg Oncol. 2015; 22:S1410-1418.

18. Slattery ML, Herrick JS, Mullany LE, Valeri N, Stevens J, Caan BJ, Samowitz W, Wolff RK. An evaluation and replication of miRNAs with disease stage and colorectal cancer-specific mortality. Int J Cancer. 2015; 137:428-438.

19. Igarashi H, Kurihara H, Mitsuhashi K, Ito M, Okuda H, Kanno S, Naito T, Yoshii S, Takahashi H, Kusumi T, 
Hasegawa T, Sukawa Y, Adachi Y, et al. Association of MicroRNA-31-5p with Clinical Efficacy of Anti-EGFR Therapy in Patients with Metastatic Colorectal Cancer. Ann Surg Oncol. 2015; 22:2640-2648.

20. Yuan W, Guo YQ, Li XY, Deng MZ, Shen ZH, Bo CB, Dai YF, Huang MY, Yang ZY, Quan YS, Tian L, Wang X. MicroRNA-126 inhibits colon cancer cell proliferation and invasion by targeting the chemokine ( $\mathrm{C}-\mathrm{X}-\mathrm{C}$ motif) receptor 4 and Ras homolog gene family, member A, signaling pathway. Oncotarget. 2016; 7:60230-60244. doi: 10.18632/ oncotarget.11176.

21. Yang H, Li Q, Niu J, Li B, Jiang D, Wan Z, Yang Q, Jiang F, Wei P, Bai S. microRNA-342-5p and miR-608 inhibit colon cancer tumorigenesis by targeting NAA10. Oncotarget. 2016; 7:2709-20. doi: 10.18632/oncotarget.6458.

22. Chen Y, Jiang J, Zhao M, Luo X, Liang Z, Zhen Y, Fu Q, Deng X, Lin X, Li L, Luo R, Liu Z, Fang W. microRNA374a suppresses colon cancer progression by directly reducing CCND1 to inactivate the PI3K/AKT pathway. Oncotarget. 2016; 7:41306-41319. doi: 10.18632/ oncotarget.9320.

23. Nosho K, Igarashi H, Nojima M, Ito M, Maruyama R, Yoshii S, Naito T, Sukawa Y, Mikami M, Sumioka W, Yamamoto E, Kurokawa S, Adachi Y, et al. Association of microRNA-31 with BRAF mutation, colorectal cancer survival and serrated pathway. Carcinogenesis. 2014; 35:776-783.

24. Ito $\mathrm{M}$, Mitsuhashi $\mathrm{K}$, Igarashi $\mathrm{H}$, Nosho $\mathrm{K}$, Naito $\mathrm{T}$, Yoshii S, Takahashi H, Fujita M, Sukawa Y, Yamamoto E, Takahashi T, Adachi Y, Nojima M, et al. MicroRNA-31 expression in relation to $\mathrm{BRAF}$ mutation, $\mathrm{CpG}$ island methylation and colorectal continuum in serrated lesions. Int J Cancer. 2014; 135:2507-2515.

25. Riquelme E, Behrens C, Lin HY, Simon G, Papadimitrakopoulou V, Izzo J, Moran C, Kalhor N, Lee JJ, Minna JD, Wistuba, II. Modulation of EZH2 Expression by MEK-ERK or PI3K-AKT Signaling in Lung Cancer Is Dictated by Different KRAS Oncogene Mutations. Cancer Res. 2016; 76:675-685.

26. Yamagishi M, Nakano K, Miyake A, Yamochi T, Kagami Y, Tsutsumi A, Matsuda Y, Sato-Otsubo A, Muto S, Utsunomiya A, Yamaguchi K, Uchimaru K, Ogawa S, et al. Polycombmediated loss of miR-31 activates NIK-dependent NFkappaB pathway in adult $\mathrm{T}$ cell leukemia and other cancers. Cancer cell. 2012; 21:121-135.

27. Zhang Y, Lin C, Liao G, Liu S, Ding J, Tang F, Wang Z, Liang X, Li B, Wei Y, Huang Q, Li X, Tang B. MicroRNA-506 suppresses tumor proliferation and metastasis in colon cancer by directly targeting the oncogene EZH2. Oncotarget. 2015; 6:32586-32601. doi: 10.18632/oncotarget.5309.

28. Kurihara H, Maruyama R, Ishiguro K, Kanno S, Yamamoto I, Ishigami K, Mitsuhashi K, Igarashi H, Ito M, Tanuma T, Sukawa Y, Okita K, Hasegawa T, et al. The relationship between EZH2 expression and microRNA-31 in colorectal cancer and the role in evolution of the serrated pathway. Oncotarget. 2016; 7:12704-12717. doi: 10.18632/oncotarget.7260.

29. Zhang Q, Padi SK, Tindall DJ, Guo B. Polycomb protein EZH2 suppresses apoptosis by silencing the proapoptotic miR-31. Cell Death Dis. 2014; 5:e1486.

30. Cottonham CL, Kaneko S, Xu L. miR-21 and miR-31 converge on TIAM1 to regulate migration and invasion of colon carcinoma cells. J Biol Chem. 2010; 285:3529335302 .

31. Chang KH, Miller N, Kheirelseid EA, Lemetre C, Ball GR, Smith MJ, Regan M, McAnena OJ, Kerin MJ. MicroRNA signature analysis in colorectal cancer: identification of expression profiles in stage II tumors associated with aggressive disease. Int J Colorectal Dis. 2011; 26:1415-1422.

32. Van Cutsem E, Kohne CH, Hitre E, Zaluski J, Chang Chien CR, Makhson A, D’Haens G, Pinter T, Lim R, Bodoky G, Roh JK, Folprecht G, Ruff P, et al. Cetuximab and chemotherapy as initial treatment for metastatic colorectal cancer. N Engl J Med. 2009; 360:1408-1417.

33. Irahara N, Baba Y, Nosho K, Shima K, Yan L, DiasSantagata D, Iafrate AJ, Fuchs CS, Haigis KM, Ogino S. NRAS mutations are rare in colorectal cancer. Diagn Mol Pathol. 2010; 19:157-163.

34. Vaughn CP, Zobell SD, Furtado LV, Baker CL, Samowitz WS. Frequency of KRAS, BRAF, and NRAS mutations in colorectal cancer. Genes Chromosomes Cancer. 2011; 50:307-312.

35. Seymour MT, Brown SR, Middleton G, Maughan T, Richman S, Gwyther S, Lowe C, Seligmann JF, Wadsley J, Maisey N, Chau I, Hill M, Dawson L, et al. Panitumumab and irinotecan versus irinotecan alone for patients with KRAS wild-type, fluorouracil-resistant advanced colorectal cancer (PICCOLO): a prospectively stratified randomised trial. Lancet Oncol. 2013; 14:749-759.

36. Tol J, Nagtegaal ID, Punt CJ. BRAF mutation in metastatic colorectal cancer. N Engl J Med. 2009; 361:98-99.

37. Liao X, Lochhead P, Nishihara R, Morikawa T, Kuchiba A, Yamauchi M, Imamura Y, Qian ZR, Baba Y, Shima K, Sun R, Nosho K, Meyerhardt JA, et al. Aspirin use, tumor PIK3CA mutation, and colorectal-cancer survival. N Engl J Med. 2012; 367:1596-1606. 